\title{
EL PROFESOR VALDALISO, A VUELTAS CON LA HISTORIA DE LA EMPRESA
}

SEBASTIÁN COLL

Universidad de Cantabria

Celebro que nuestros artículos hayan despertado el interés que evidencia la réplica de Valdaliso, aunque siento que a éste su lectura le haya «dejado un tanto insatisfechom. No voy a decir que el sentimiento sea reciproco, aunque eso no significa, desde luego, que esté de acuerdo con todo lo que él dice. ¿Cómo voy a estarlo, si dedica gran parte de su artículo a meterse conmigo?

El breve espacio de un articulo obliga siempre a efectuar una selección. Teniendo esto en cuenta, me parece muy bien que Valdaliso, en el suyo, mencione autores y corrientes que nosotros habiamos omitido en los nuestros, pero disiento en que se tome omisión como sinónimo de deficiencia: soy perfectamente consciente de haber efectuado una selección - así lo advertia, por ejemplo (Coll, 1991, 264) al aclarar, subrayando las palabras, que el panorama ofrecido no era exhaustivo, y lo manifestaba desde el propio título del articulo-, pero no comparto la idea de que tal selección está mal hecha, o al menos tan mal hecha como supone nuestro crítico.

¿Qué pruebas pueden usarse en este pleito? Pues veamos una. El artículo que publiqué en solitario, y que tanto disgusta a Valdaliso, tenia dos partes. En la primera uno podia encontrar, efectivamente, un resumen de la literatura de carácter teórico; ese resumen era declaradamente incompleto, telegráfico y lo que se quiera, pero al menos permitia - creo- hacerse una idea del contenido de esa literatura. Asimismo, en esa primera parte se podia encontrar otra referencia - todavia más breve e incompleta - a obras propiamente históricas. Pues bien, lo que realmente sorprende en el artículo de Valdaliso es que, después de criticar extensamente ambos resúmenes, aparentemente no tenga nada que decir sobre la segunda parte del artículo, en la cual se presentaba el borrador - una vez más incompleto y provisional- para un curso de historia de la 
empresa vertebrado de acuerdo con esos antecedentes teóricos e historiográficos. Uno pensaria que, con tan defectuosos presupuestos, la segunda parte del articulo habría de ser la más discutida; pero no parece ser asi, y desde luego en el artículo de Valdaliso tampoco se encuentra una propuesta alternativa.

En el fondo, la sorpresa no es tal. ¿Por què? En nuestra materia, por un lado estamos aquellos que pensamos que con el empleo de la teoria económica la historia económica llega mucho más lejos, y luego están quienes - como Valdaliso- desconfian de la teoría y relativizan su papel con la afirmación de que ésta es sólo «una de las varias que existen en el mercadom. La posición no es nueva: es simplemente la vieja posición historicista, la misma de la escuela histórica alemana. Si vamos al examen de los argumentos de unos y otros, posiblemente no encontraremos vencedores en esa polémica: ésta es vieja y recurrente, precisamente por ello. Pero el resultado de la polémica se dirime en otro terreno: en el de los frutos que proporciona, en forma de hipótesis y de resultados, la aplicación de la teoria al análisis de los hechos. De eso trataba precisamente esa segunda parte de mi articulo, aunque desde luego está muy lejos de constituir el mejor ejemplo imaginable. Sobre la marcha, se me ocurre que a lo mejor soy injusto al pedir a Valdaliso ideas para una asignatura de historia de la empresa. La intención de mi artículo era la de estimular y sugerir; pero la lectura de Valdaliso me hace dudar de que ésa haya sido también la intención suya.

Abundando en la idea apuntada más arriba, nuestro crítico se sitúa en la mejor tradición historicista cuando invoca teorias alternativas, afirmando - ¿cómo no?- que éstas son «jóvenes y todavía poco desarrolladas»; por su parte, el enfoque costes de transacción constituye, según él, «un aparato analitico en construcción, con una serie de limitaciones y deficienciasm. Dejando a un lado ahora el que su caracterización sea o no exacta, los términos son casi los mismos en los dos casos, pero con una sutil diferencia: por alguna razón, lo que para una teoria es culpa, para otra resulta ser atenuante. Sin embargo, y básicamente, el mensaje de nuestro autor es antiteórico desde el momento en que, para él, «la prioridad fundamental aqui y ahora es sobre todo producir estudios de historia empresarial», en tanto que seguir nuestro enfoque significa «empobrecer las líneas de desarrollo de la disciplina».

A este respecto me viene a la memoria que, al redactar el artículo de Tortella y Coll, barajamos como posible título uno que rezase «De las historias de empresas a la historia de la empresa: estado de la cuestión en Españan. Ese título finalmente se descartó, por razones que no vienen al caso. Sin embargo, lo que propone Valdaliso es, literalmente, seguir escribiendo historias de empresas en lugar de una -que no excluye otras- historia de la empresa. Por ello, después de afearnos reiteradamente nuestra visión «sesgada», «incompleta», 
"empobrecedora», «reduccionista» y «metafísica», y de criticarnos por «confundir la especie con el género» y por «reducir peligrosamente el concepto y el objeto de la historia», habrá que preguntarse finalmente quién es el que está empobreciendo la disciplina.

Hay otros aspectos de ese mensaje antiteórico que también me llaman la atención. Por ejemplo, Valdaliso entiende que servirse de la teoria en la investigación significa reducir esta última a una contrastación de la teoría, y dedica varios párrafos a criticar ese «reduccionismo». Lo menos que se puede decir es que una confusión suya está atribuyéndonos un defecto imaginario. En efecto, también se puede emplear la teoria para otros fines que no sean su propia contrastación: por ejemplo, para hacerla avanzar. Si la teoría económica no responde a todas las preguntas que nos podamos hacer los historiadores $-o$ a todas las preguntas relativas al largo plazo, que viene a ser lo mismo-, el papel de la historia económica no creo que sea el de echar por la borda la teoria, sino el de ayudar a construirla. No voy a insistir en que el corpus existente de la teoria económica proporciona el mejor fundamento para esa construcción, simplemente porque nadie en su sano juicio justifica lo que es evidente.

Para terminar con este tipo de cuestiones, en el artículo de Valdaliso se incurre en una ingenuidad, la de pensar que la investigación empirica, sin la guia de preguntas e hipótesis procedentes de la teoría, sea capaz de llevarnos a alguna parte. Y a continuación, descendiendo de la teoría en general a una teoría en concreto, no deja de llamar la atención que la teoria de la empresa que conocemos sea acusada de ocuparse de cuestiones «casi metafísicas» cuando se refiere a la naturaleza y razón de ser de la empresa. ¿De qué otra cosa supone Valdaliso que debe tratar una teoria de la empresa?

Luego hay otros aspectos comentables en su artículo:

Más o menos explicitamente - y con el mismo espíritu patrimonial que exhibe en sus circulares a la profesión-, Valdaliso nos acusa de querer sacar a la historia de la empresa fuera de la historia económica, a cuyo respecto habrá que decir que o no nos entiende o no quiere entendernos. La historia de la empresa nos describe, al nivel microeconómico, una serie de procesos que resultan relevantes para la historia económica. Por ejemplo -y, por favor, sólo como ejemplo-, la historia de la empresa proporciona una descripción, a ese nivel, de las mejoras organizativas, y las mejoras organizativas constituyen una de las fuentes del crecimiento de la productividad de los factores, y, por tanto, del crecimiento económico. Por eso - ¿y tendremos que añadir que no sólo por eso? - la historia de la empresa es importante para la historia económica, y por ello también Valdaliso se equivoca cuando sitúa a «las relativas a la organización de las empresas» entre las cuestiones secundarias para la historia de la empresa. 
Lo anterior no excluye que la historia de la empresa pueda estudiarse como materia con entidad propia, y ayuda a los futuros licenciados en empresariales a entender mejor a la empresa y al papel de la misma en el crecimiento económico, o a vacunarse contra la esclerosis. «Aspirar a ampliar nuestro conocimiento sobre el pasado económico» no tiene por qué ser, como supone Valdaliso, el único objetivo de la historia de la empresa, y desde luego esa ampliación de nuestro conocimiento del pasado si que «no puede ser un fin en sí mismon como - a falta de otros ulteriores- parece deducirse de su artículo. En definitiva, discutir si la historia de la empresa es o no es parte de un territorio más amplio, decir que nunca debió salir fuera de la historia económica o que «no tiene que dejar nunca de ser historia económica» - el subrayado es suyoresulta sencillamente pueril, y los historiadores económicos, como cultivadores de una parcela situada entre dos territorios mayores que eventualmente podrian disputársela, deberiamos saberlo ya a estas alturas.

También nos reprocha Valdaliso que en el artículo conjunto de Tortella y Coll no citemos a un solo autor de lo que llamamos «literatura de denuncia», $y$ no le falta razón. Pero no lo vamos a hacer, porque bastante polémica hemos generado ya sin hacerlo, y en la medida en que pretendamos polemica la queremos cientifica, no personal.

Por último, y comoquiera que las andanadas de Valdaliso no se limitan a nuestras modestas personas, me voy a permitir algunos comentarios a este respecto. Dice Valdaliso que «no podemos plantearnos aqui las mismas direcciones de investigación que en Estados Unidos», para añadir, sorprendentemente, «direcciones que dicho sea de paso no son las que predominan en la actualidad». Sorprende que nuestro crítico, aparentemente tan informado de la historiografia empresarial norteamericana, considere que la misma se encuentra desfasada, pero eso es literalmente lo que dice su frase. Menos mal - para Oli. ver Williamson y para el «estrecho" Alfred Chandler, el ganador de los premios Bancroft y Pulitzer- que por dos veces aclara que «no es (su) propósito entrar a valorar la obra de Chandler y Williamson», y que «no (le) interesa dis. cutir la mayor o menor validez de las conclusiones de Chandler». Únicamente hubiéramos deseado la misma condescendencia para con Ronald $\mathrm{H}$. Coase, cuya «metafísica» obra teórica, por lo visto, ha necesitado ser «notablemente mejorada (...) para intentar adecuarse mejor a la realidad a estudiarm. Lamentablemente, los responsables alla en Suecia no debian tener este dato cuando decidieron, en 1991, conceder a Coase el Nobel de economia -precisamente cuando se encontraba en prensa mi artículo, en el que recomendaba a los historiadores de la empresa inspirarse en la teoria iniciada por Coase. 